\title{
Influence of heat treatment on microstructure and nanohardness of TiAl alloy solidified under high pressure
}

\author{
Dong-dong Zhu', ${ }^{1,}$ *Duo Dong1, * *Jie-ren Yang ${ }^{3}$, Li Liu', Xiao-hong Wang ${ }^{1}$, Yuan-xiang Zhang', Zun-jie Wei ${ }^{2}$ \\ 1. Key Laboratory of Air-driven Equipment Technology of Zhejiang Province, Quzhou University, Quzhou 324000, China \\ 2. School of Materials Science and Engineering, Harbin Institute of Technology, Harbin 150001, China \\ 3. State Key Laboratory of Solidification Processing, Northwestern Polytechnical University, Xi'an 710072, China
}

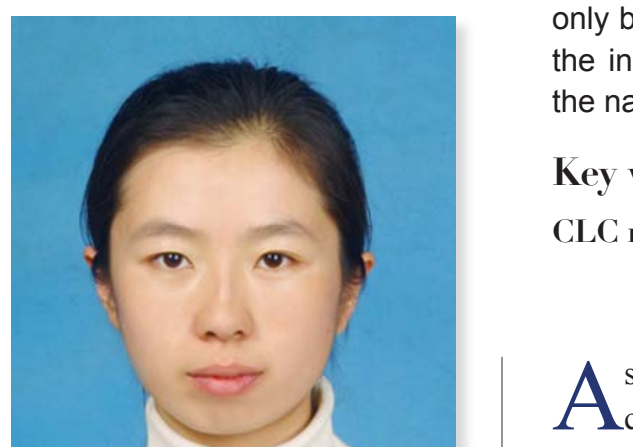

Abstract: The Ti-48at.\%Al alloy solidified under different pressures was prepared using a tungsten-carbide six-anvil apparatus and then heat treated at different temperatures. The effect of heat treatment on microstructure and mechanical properties of high pressure solidified Ti-48Al alloy was investigated. The results showed that the phase constitution of the Ti-48Al alloy solidified under high pressure did not change after heat treatment. After $1,100{ }^{\circ} \mathrm{C} / 12 \mathrm{~h} \mathrm{AC}$ (air cooling), the value of c/a showed a slight increase. The Widmanstätten structure was formed in the samples solidified under $2 \mathrm{GPa}$ and $4 \mathrm{GPa}$. More defects were found in the highpressure samples. The volume fraction of $\alpha_{2}$ particles increased with an increase in pressure. After $1,150{ }^{\circ} \mathrm{C} / 4 \mathrm{~h} \mathrm{AC}$, the discontinuous coarsening phenomenon could only be found in the $4 \mathrm{GPa}$ solidified samples. The formation of $\alpha_{2}$ phase can lead to the increase of nanohardness. Compared with the samples before heat treatment, the nanohardness increased about 1.0-1.2 GPa.

Key words: heat treatment; TiAl; microstructure; nanohardness

CLC numbers: TG146.23; Document code: A; Article ID: 1672-6421 2020 06-435-06

\section{*Duo Dong}

Born in 1983, Associate Professor. Her research interests mainly focus on the preparation of TiAl alloys, the microstructure evolution and mechanical behaviors of TiAl alloy during conventional solidification processes, effect of high pressure on the phase transformation and solidification theory.

E-mail: dongduohit@163.com

** Jie-ren Yang

E-mail: yangjieren@nwpu.edu.cn

Received: 2020-06-15

Accepted: 2020-09-24

A s potential high-temperature structural materials, TiAl intermetallics have received onsiderable attention due to their high specific strength and modulus, high oxidation and creep resistance and low density ${ }^{[1-3]}$. However, their application has been restricted due to their intrinsic brittleness and poor room temperature ductility ${ }^{[4-5]}$. Many efforts have been made to improve the comprehensive properties of TiAl alloy. Alloying, as one of the effective methods, has been widely performed and reported ${ }^{[6-8]}$. The addition of $\mathrm{Cr}$ and $\mathrm{V}$ can enhance the room temperature ductility of TiAl intermetallics ${ }^{[9-11]}$. According to Yang's study ${ }^{[12]}$, the addition of Ru in TiAl alloys leads to the precipitation of $\tau_{1}$ phase after the formation of $\alpha$ phase, which can improve both the ductility and strength.

With the development of high-pressure technology, pressure as another crucial parameter has been widely studied in recent years ${ }^{[13-14]}$. When high pressure was applied to the solidification process, it led to the decrease of diffusion coefficient, and the increase of nucleating and growth rate. Hence, metastable phase can usually be formed, and the mechanical properties show a great increase after high pressure solidification. According to Jie's study ${ }^{[15]}$, the ultimate tensile strength (UTS) of Al-32Mg is about $18.4 \mathrm{MPa}$ by conventional solidification, and the UTS was remarkably improved to $263.6 \mathrm{MPa}$ when solidified under $3 \mathrm{GPa}$. Liu's study ${ }^{[16]}$ showed that the average Vickers hardness increased from $89 \mathrm{HV}$ to $183 \mathrm{HV}$ when the solidification pressure increased from atmospheric pressure to $3 \mathrm{GPa}$. High pressure can also change the primary phase ${ }^{[17]}$, and decrease the lamellar spacing of TiAl alloys, which is beneficial to the mechanical properties. 
Extensive studies indicate that heat treatment has also been used to modify the microstructure and hence improves the mechanical properties of TiAl alloy ${ }^{[18-19]}$. Zhang et al. ${ }^{[19]}$ reported that after five cycles of heat treatment, the coarse full lamellae completely divided to small lamellar microstructure and the ductility and tensile strength showed a great increase. Once the metastable phase was formed under high pressure, the stability of the microstructure also showed a great influence on the mechanical properties of TiAl alloys. However, until now, a comprehensive understanding of the influence of heat treatment on high pressure TiAl alloy samples is still lacking. Therefore, in this study, the effect of heat treatment on the microstructure evolution and mechanical properties of high pressure solidified Ti-48at.\%Al alloy was investigated.

\section{Experimental}

The Ti-48at.\%Al alloys were prepared using an induction skull melting furnace. The samples for high pressure solidification were cut into $\Phi 20 \mathrm{~mm} \times 9 \mathrm{~mm}$ by an electrical discharged machine. The experiment was carried out on a high pressure six-anvil apparatus. This consists of temperature and pressure controlling systems which can generate pressure to $10 \mathrm{GPa}$ and temperature to $1,800{ }^{\circ} \mathrm{C}$. The samples were heated in a graphite furnace and boron nitride was used to segregate TiAl alloys and graphite furnace. Pyrophillite was used as a pressure transmitting medium. The pressure was first increased to 2 and $4 \mathrm{GPa}$, and then the sample was heated to the melting point. The detailed experimental procedure of high pressure solidification was described in previous studies ${ }^{[17]}$. After high pressure solidification, the samples were cut into $5 \mathrm{~mm} \times 5 \mathrm{~mm} \times 1 \mathrm{~mm}$ and then sealed in evacuated quartz for heat treatment. The heat treatment was carried out at a heating rate of $20{ }^{\circ} \mathrm{C} \cdot \mathrm{min}^{-1}$ to $1,100{ }^{\circ} \mathrm{C}$ and $1,150{ }^{\circ} \mathrm{C}$, respectively, holding for different times, and then air cooled (AC).

The phases constitution of the samples after heat treatment was characterized using a Bruke D 8 advanced X-ray diffractometer with monochromatic $\mathrm{Cu}-\mathrm{K} \alpha$ radiation. The microstructure observation was carried out on polished samples with a scanning electronic microscope (SEM). Thin foils for transmission electron microscopy (TEM) observations were prepared by twin-jet polishing with a solution of $60 \%$ methanol, $34 \%$ butanol and $6 \%$ perchloric acid and then investigated using the Philips CM12 TEM working at $200 \mathrm{kV}$.

Nanohardness experiments were performed using a Nano Indenter XP tester at room temperature, which offers a direct measurement of elastic modulus and nanohardness during the test. A standard Berkovich indenter with a normal angle of $65.3^{\circ}$ and radius of $20 \mathrm{~nm}$ was used for the test. Prior to the nanohardess tests, each sample was ground and polished. The force resolution of the tester is about $50 \mathrm{nN}$. At least 10 measurements were conducted to get the average nanohardness of each sample.

\section{Results and discussion}

\subsection{Phase constitution of Ti-48Al alloy solidified under different pressures after heat treatment}

Figure 1 shows the XRD patterns of Ti-48Al alloy solidified under different pressures after heat treatment. It can be seen that all the samples consist of $\gamma$-TiAl phase and $\alpha_{2}-\mathrm{Ti}_{3} \mathrm{Al}$ phase after $1,100{ }^{\circ} \mathrm{C} / 12 \mathrm{~h} \mathrm{AC}$. Previous study showed that the Ti48Al alloy samples solidified under different pressures consist of $\gamma$-TiAl phase and $\alpha_{2}-\mathrm{Ti}_{3} \mathrm{Al}$ phase ${ }^{[20]}$, which indicates that heat treatment does not change the phase constitution of the samples solidified under different pressures. The lattice parameters were calculated by Bragg equation with the XRD results. Figure 2 shows the c/a value of $\gamma$ phase before and after heat treatment. The c/a ratio represents the tetragonality of $\gamma$ phase. When solidified under high pressure, the lattice is compressed, and the tetragonality shows a slight decrease. After $1,100{ }^{\circ} \mathrm{C} / 12 \mathrm{~h} \mathrm{AC}$, the lattice distortion was recovered, and the c/a ratio shows a slight increase.

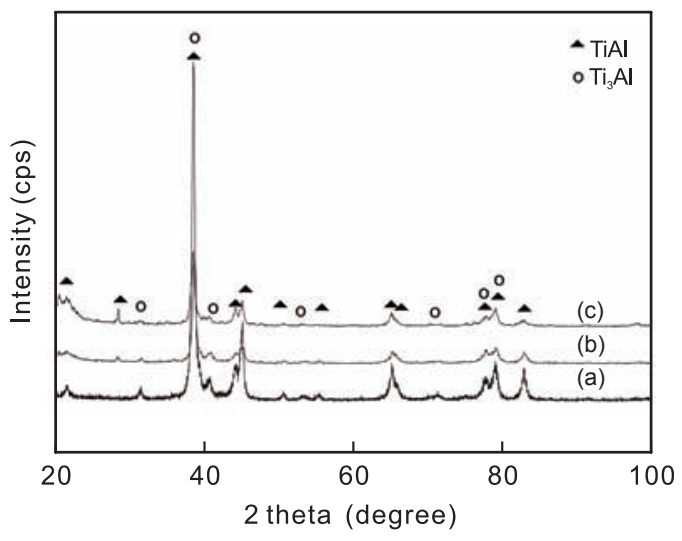

Fig. 1: XRD patterns of Ti-48Al alloy solidified under different pressures annealed at $1,100^{\circ} \mathrm{C} / 12 \mathrm{~h} \mathrm{AC}$ : (a) conventional solidification; (b) $2 \mathrm{GPa}$; (c) $4 \mathrm{GPa}$

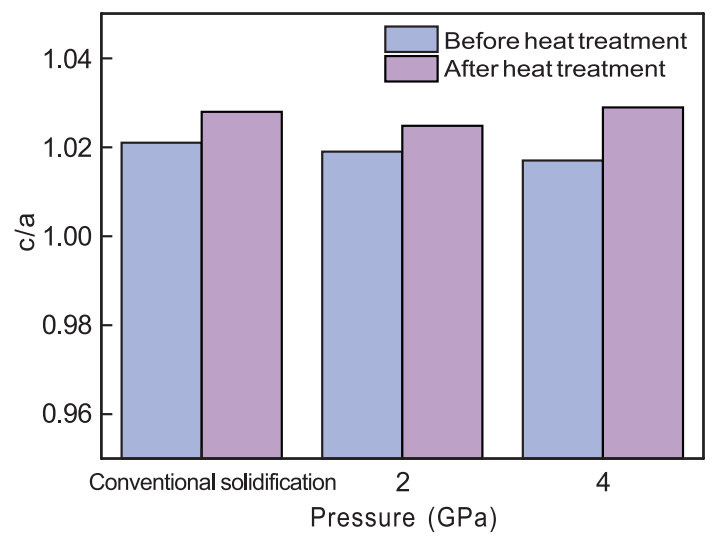

Fig. 2: c/a value of $Y$ phase before and after $1,100^{\circ} \mathrm{C} / 12 \mathrm{~h}$ heat treatment

\subsection{Effect of heat treatment on microstructure of Ti-48Al alloy solidified under different pressures}

The microstructures of the Ti-48Al alloy samples solidified under different pressures after heat treatment $\left(1,100{ }^{\circ} \mathrm{C} / 12 \mathrm{~h}\right.$ 
AC) are shown in Fig. 3. After heat treatment, the volume fraction of $\gamma$ phase decreases with the increasing pressure. At $4 \mathrm{GPa}$, it consists of near fully lamellar structure. Combined with our previous study ${ }^{[17]}$, before heat treatment, the volume fraction of $\gamma$ phase decreases from $17.0 \%$ by conventional solidification to $0.69 \%$ at $4 \mathrm{GPa}$. This indicates that after heat treatment, the volume fraction of $\gamma$ phase also decreases with pressure. However, Widmanstätten structure was formed in the $2 \mathrm{GPa}$ and $4 \mathrm{GPa}$ solidified samples after heat treatment. According to Dey's study ${ }^{[21]}$, the Widmanstätten lath, which also comprised of $\alpha_{2}$ and $\gamma$ lamellae, is found to have the same orientation relationship with the lamellae structure. The orientation relationship is given by Blackburn ${ }^{[2]}$ : $(0002)_{\alpha 2} / /\{111\}_{\gamma}$. For conventionally solidified samples, the Widmanstätten lath can only be formed when heated to $\alpha+\gamma$ phase region and then cooled at the intermediate rate. During the heating process, $\alpha_{2}$ firstly disordered to $\alpha$ phase. According to the TiAl phase diagram ${ }^{[12]}, \alpha_{2}$ firstly transformed to $\alpha$ phase during the heating process. At the same time, new $\alpha$ phase would nucleate and grow on the (111) plane of the previous $\gamma$ lamellae. In the subsequent cooling process, the newly formed $\alpha$ phase transformed to Widmanstätten lath. For conventionally solidified samples, the $\alpha_{2}$ phase can hardly transform to $\alpha$ phase at $1,100{ }^{\circ} \mathrm{C}$, so Widmanstätten lath can scarcely be found after heat treatment at $1,100{ }^{\circ} \mathrm{C}$. High pressure leads to the decrease of lamellar spacing, and the length-diameter ratio of $\alpha_{2}$ and $\gamma$ phase increases, which is beneficial to Rayleigh's breakdown of lamellar structure in TiAl alloys. So, the high pressure solidified samples would be more unstable. The decreasing of lamellar spacing also leads to the increase of phase boundary and dislocation after high pressure, which can be used as effective heterogeneous nucleation sites for $\alpha$ phase. This can significantly reduce the nucleation barrier. After $1,100{ }^{\circ} \mathrm{C} / 12 \mathrm{~h} \mathrm{AC}, \alpha$ phase can be formed on the (111) crystal plane of $\gamma$ lamellae in high pressure samples. During subsequent cooling, the newly formed $\alpha$ phase would transform to Widmanstätten lath.
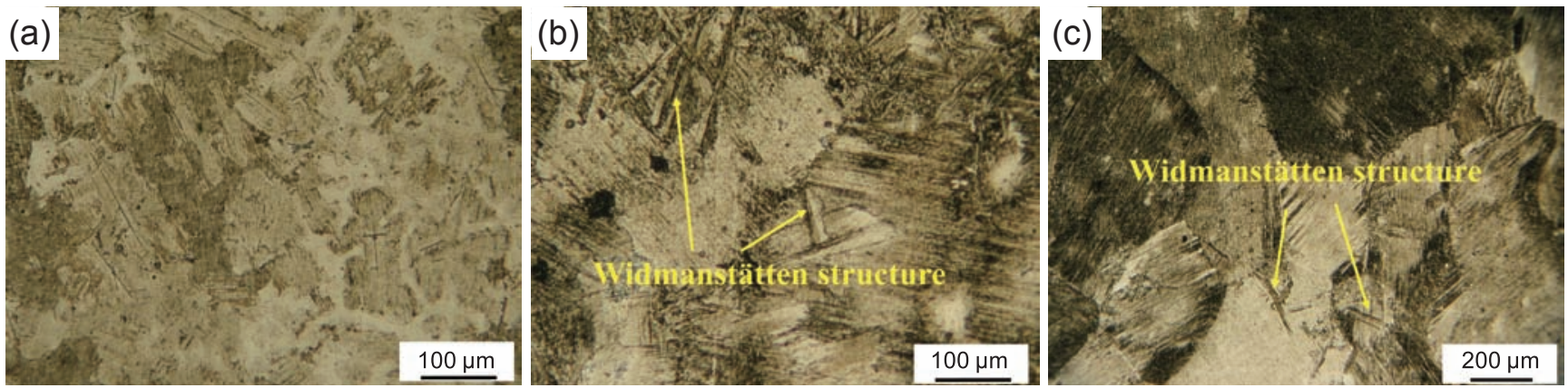

Fig. 3: Optical microstructure of Ti-48Al alloy solidified under different pressures after annealing at $1,100{ }^{\circ} \mathrm{C} / 12 \mathrm{~h}$ AC: (a) conventional solidification; (b) $2 \mathrm{GPa}$; (c) $4 \mathrm{GPa}$

It can also be seen from Fig. 4 that after $1,100{ }^{\circ} \mathrm{C} / 12 \mathrm{~h}$ AC heat treatment, very fine $\alpha_{2}$ particles are distributed in the conventionally solidified samples. At $2 \mathrm{GPa}$, the volume
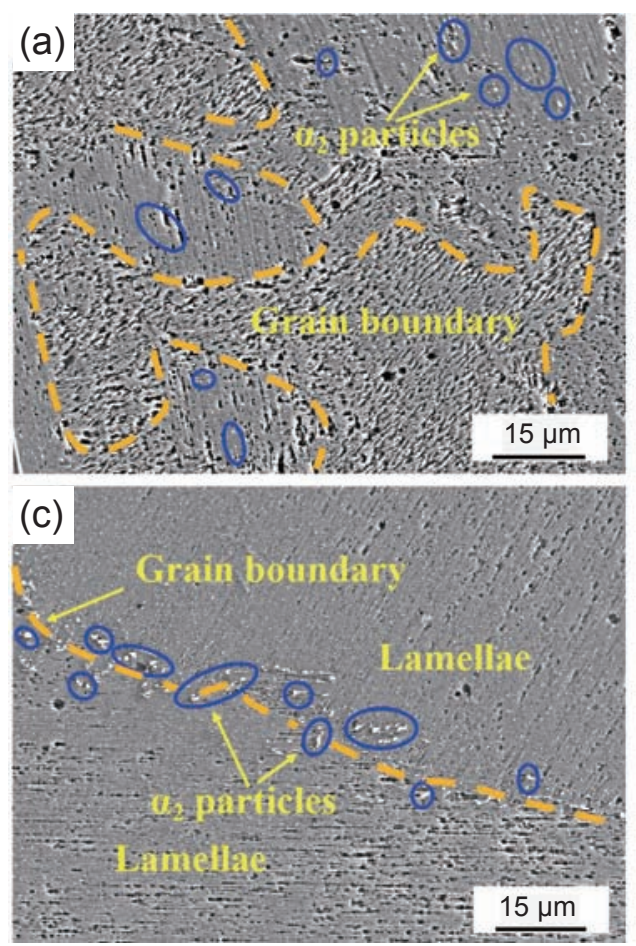

fraction and grain size of $\alpha_{2}$ particles show a certain increase. At $4 \mathrm{GPa}$, the $\alpha_{2}$ particles coarsen greatly and are mainly distributed at the grain boundary.

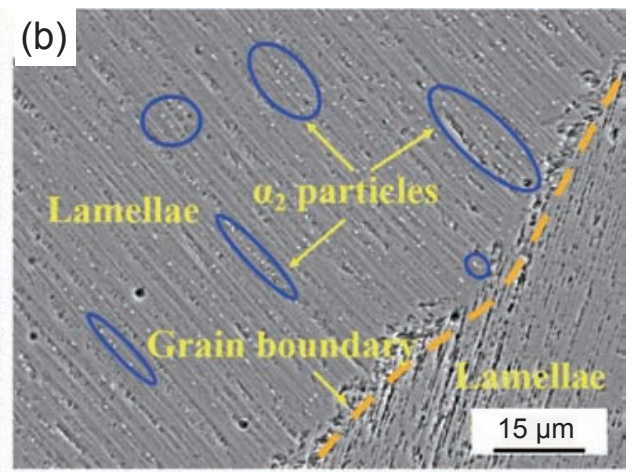

Fig. 4: Microstructure of Ti-48Al alloy solidified under different pressures after annealing at $1,100^{\circ} \mathrm{C} / 12 \mathrm{~h} \mathrm{AC}$ : (a) conventional solidification; (b) $2 \mathrm{GPa}$; (c) $4 \mathrm{GPa}$ 
To further study the microstructure evolution of high pressure solidified samples after heat treatment, TEM observations were conducted. TEM observations show that $\alpha_{2}$ particles are scarcely found in the $\gamma$ phase by conventional solidification, as shown in Fig. 5(a). Black $\alpha_{2}$ particles are homogeneously distributed in the $\gamma$ phase of the samples solidified under $4 \mathrm{GPa}$. It can be seen that after heat treatment, the lamellar spacing also decreases with increasing pressure. According to Fig. 5, the dislocations density is also different when Ti-48Al alloy was solidified under different pressures and then heat treated at $1,100{ }^{\circ} \mathrm{C} / 12 \mathrm{~h} \mathrm{AC}$. The dislocations are mainly distributed in the $\gamma$ phase, and the higher the solidification pressure, the greater the dislocation density. The increasing of dislocation density is beneficial to the nucleation of new phases. So, the samples solidified under high pressure is more likely to form Widmanstätten lath. A previous study ${ }^{[23]}$ showed that discontinuous coarsening phenomenon can be found after heat treatment. However, such phenomena were not found in the Ti-48Al alloy after annealing at $1,100{ }^{\circ} \mathrm{C}$. It can also be seen that after annealing, the interface between $\alpha_{2}$ and $\gamma$ phase in the lamellae of conventional solidified samples is still straight. More defects, such as curved interface, interface dissolution and edge migration, can be found in the high pressure solidified samples.
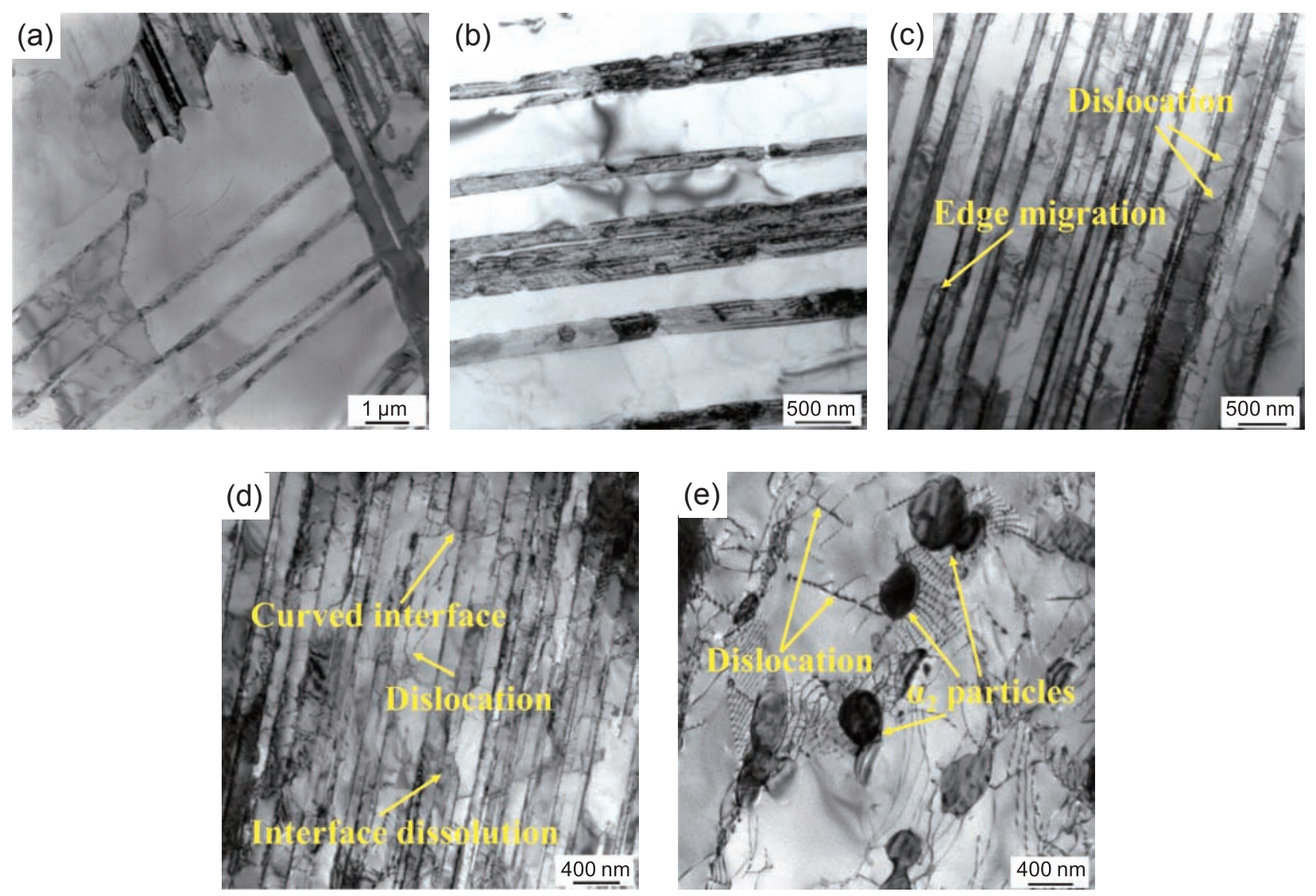

Fig. 5: TEM images of Ti-48Al solidified under different pressures after 1,100 ${ }^{\circ} \mathrm{C} / 12 \mathrm{~h} \mathrm{AC}$ : (a and b) conventional solidification; (c) $2 \mathrm{GPa}$; (d and e) $4 \mathrm{GPa}$

Figure 6 shows Ti-48Al alloy solidified under different pressures and then heat treated at $1,150{ }^{\circ} \mathrm{C} / 4 \mathrm{~h} \mathrm{AC}$. It can be seen that discontinuous coarsening was observed in the $4 \mathrm{GPa}$ solidified samples. According to the Gibbs-Thomson theory, the diffusion of atoms would lead to the migration of the defects, then different kinds of coarsening in the lamellar structure can be found. According to Livingston's ${ }^{[24]}$ study on discontinuous coarsening mechanism of the lamellar structure, finer initial lamellae leads to the higher coarsening rate. Due to the decrease of lamellar spacing after high pressure solidification, the high pressure solidified samples would be more unstable. The decrease of lamellar spacing would also lead to the increase of chemical energy in high pressure samples, which makes the high pressure samples more unstable.

\subsection{Effect of heat treatment on nanohardness of Ti-48Al alloy solidified under different pressures}

Figure 7 shows the hardness-depth curves obtained from the samples after $1,100{ }^{\circ} \mathrm{C} / 12 \mathrm{~h} \mathrm{AC}$. The deviations of the curves are small when the indentation depth was $800 \mathrm{~nm}$, so the average hardness is calculated at this depth. The average hardness values are listed in Table 1 and the values before heat treatment are also listed for comparison. After heat treatment, the hardness increases with the increasing pressure. Seung's study ${ }^{[25]}$ showed that the fine $\alpha_{2}$ lamellae can act as a reinforcement restricting the dislocation gliding, and the decrease of lamellar spacing led to the increase of lamellar boundary, which is beneficial to the increase of nanohardness. 

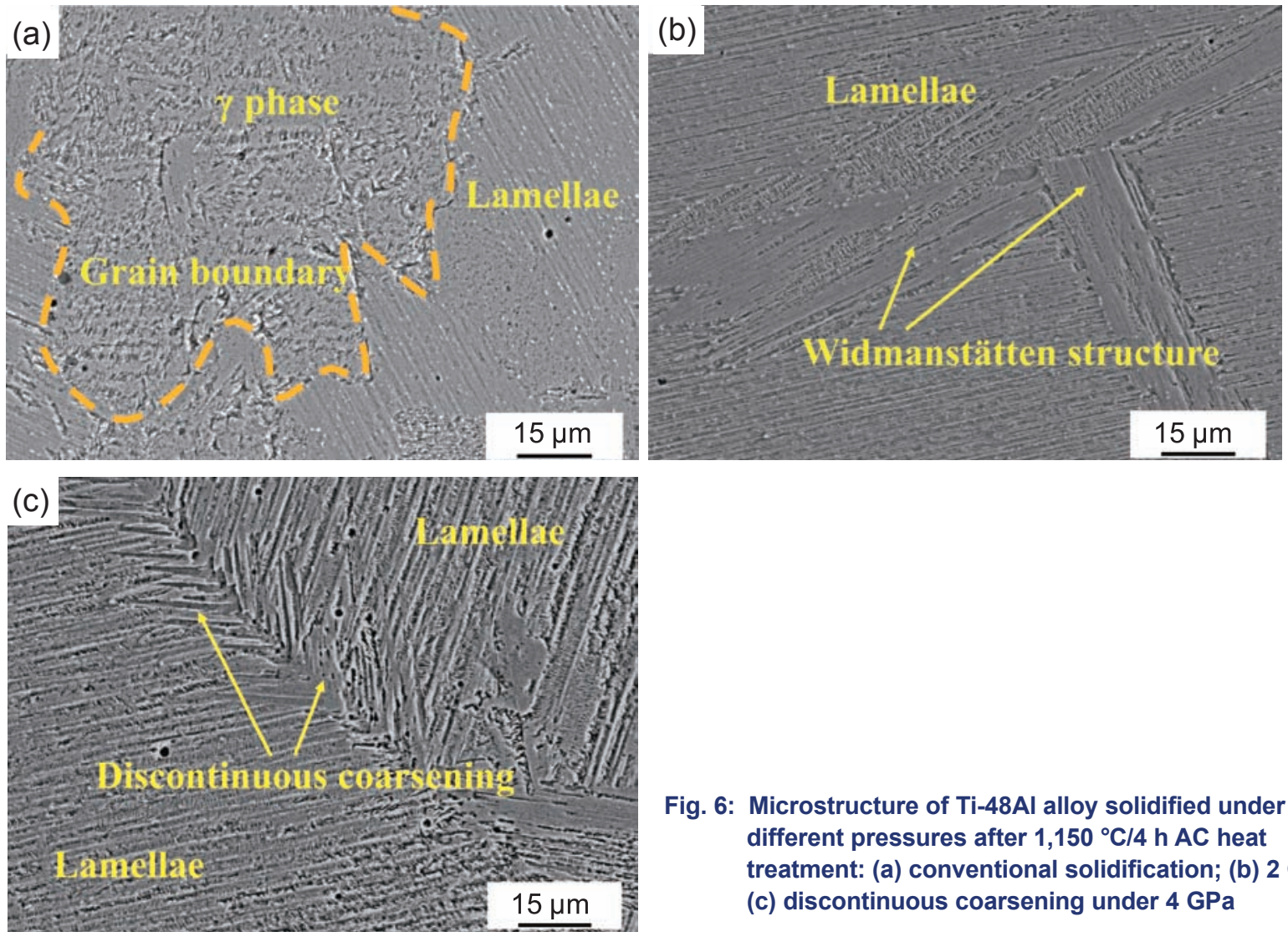

Fig. 6: Microstructure of Ti-48Al alloy solidified under different pressures after $1,150{ }^{\circ} \mathrm{C} / 4 \mathrm{~h} \mathrm{AC}$ heat treatment: (a) conventional solidification; (b) $2 \mathrm{GPa}$; (c) discontinuous coarsening under $4 \mathrm{GPa}$

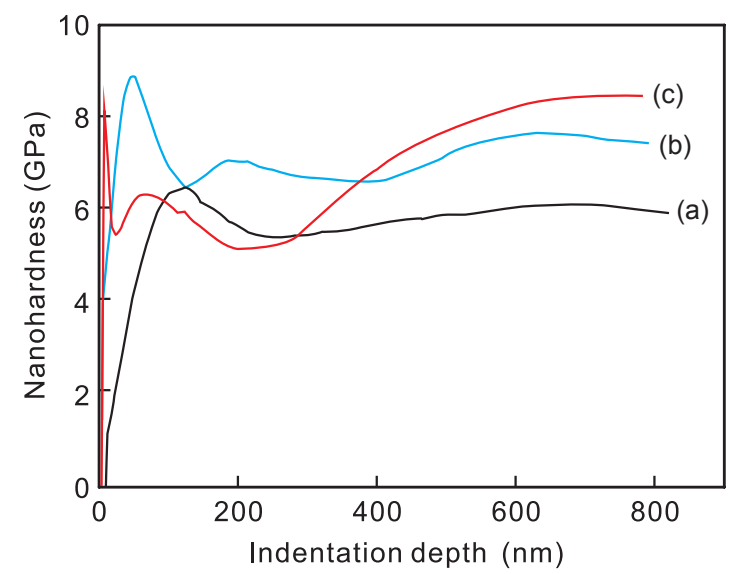

Fig. 7: Curves of nanohardness vs. indentation depth of lamellar structures of $1,100^{\circ} \mathrm{C} / 12 \mathrm{~h}$ AC heat treated Ti-48Al alloys solidified under different pressures: (a) conventional solidification; (b) $2 \mathrm{GPa}$; (c) $4 \mathrm{GPa}$

Table 1: Nanohardness of as-cast and heat treated Ti-48Al alloy solidified under different pressures

\begin{tabular}{ccc|}
\hline Samples & \multicolumn{2}{c|}{ Nanohardness (GPa) } \\
\hline $\begin{array}{c}\text { Conventional } \\
\text { solidification }\end{array}$ & $4.98 \pm 0.10$ & $5.92 \pm 0.15$ \\
$2 \mathrm{GPa}$ & $6.23 \pm 0.11$ & $7.50 \pm 0.10$ \\
$4 \mathrm{GPa}$ & $7.48 \pm 0.16$ & $8.46 \pm 0.21$ \\
\hline
\end{tabular}

After heat treatment, the nanohardness of samples solidified under $4 \mathrm{GPa}$ increased by about $43 \%$, compared with that of conventional solidification. Compared with the samples before heat treatment, the nanohardness increased about 1.0-1.2 GPa. It is reported that $\alpha_{2}$ phase is harder than $\gamma$ phase ${ }^{[26]}$, therefore, after high pressure solidification, the formation of $\alpha_{2}$ phase can also lead to the increase of nanohardness.

\section{Conclusions}

(1) After $1,100{ }^{\circ} \mathrm{C} / 12 \mathrm{~h} \mathrm{AC}$, the phase constitution of the high pressure solidified samples is not changed, while the c/a of $\gamma$ phase shows a slight increase.

(2) After $1,100{ }^{\circ} \mathrm{C} / 12 \mathrm{~h} \mathrm{AC}$, the Widmanstätten structure is formed only in the high pressure solidified samples. The volume fraction of $\alpha_{2}$ particles increases with the increasing pressure. After $1,150{ }^{\circ} \mathrm{C} / 4 \mathrm{~h} \mathrm{AC}$, discontinuous coarsening phenomenon can be found in the $4 \mathrm{GPa}$ solidified samples. TEM observation shows that more defects, such as curved interface, interface dissolution and edge migration, are found in the high pressure samples, which makes the high pressure samples more unstable.

(3) The formation of $\alpha_{2}$ phase can also lead to the increase of nanohardness. Compared with the samples before heat treatment, the nanohardness of the samples after heat treatment increases about 1.0-1.2 GPa. 


\section{Acknowledgments}

This work was financially supported by the Zhejiang Province Natural Science Foundation of China (Grant No. LY18E010003) and the National Natural Science Foundation of China (Grant Nos.: 51801112, 51501100).

\section{References}

[1] Fan J L, Li X Z, Su Y Q, et al. Microstructure evolution of directionally solidified Ti-46Al-0.5W-0.5Si alloy. Journal of Crystal Growth, 2011, 337(1): 52-59.

[2] Shu S L, Qiu F, Tong C Z, et al. Effects of Fe, Co and N elements on the ductility of TiAl alloy. Journal of Alloys and Compounds, 2014, 617: 302-305.

[3] Shi C C, Zhang K F, Lu Z, et al. Microstructure evolution and mechanical properties of Ti46.5Al2 $\mathrm{Cr} 1.8 \mathrm{Nb}-(\mathrm{W}, \mathrm{B})$ alloys fabricated by spark plasma sintering and pulse current assisted isothermal forging. Materials Science and Engineering: A, 2019, 747: 98-110.

[4] Wang Q, Chen R R, Yang Y H, et al. Creep behavior of high-nb tial alloy at $800-900^{\circ} \mathrm{C}$ by directional solidification. Advanced Engineering Materials, 2018, 20(3): 1700734.

[5] Xu Y, Shi P F, Qu J, et al. Oxidation behaviors and self-healing performance of MoSiAlY coating on Y-TiAl substrate by a surface alloying method. Vacuum, 2019, 165: 148-156.

[6] Chen R R, Zheng D S, Ma T F, et al. Effects and mechanism of ultrasonic irradiation on solidification microstructure and mechanical properties of binary TiAl alloys. Ultrasonics Sonochemistry, 2017, 38: 120-133.

[7] Ye L H, Wang H, Zhou G, et al. Phase stability of TiAl-X (X=V, Nb, $\mathrm{Ta}, \mathrm{Cr}, \mathrm{Mo}, \mathrm{W}$, and $\mathrm{Mn}$ ) alloys. Journal of Alloys and Compounds, 2020, 819: 153291.doi.org/10.1016/j.jallcom.2019.153291.

[8] Chen $\mathrm{H}$, Li X, Chen Z, et al. Investigation on electronic structures and mechanical properties of $\mathrm{Nb}$-doped $\mathrm{TiAl}_{2}$ intermetallic compound. Journal of Alloys \& Compounds, 2019, 780: 41-48.

[9] Chen $\mathrm{Y} \mathrm{H}$, Roa J J, Yu C H, et al. Enhanced thermal stability and fracture toughness of TiAIN coatings by $\mathrm{Cr}, \mathrm{Nb}$ and V-alloying. Surface and Coatings Technology, 2018, 342: 8593.

[10] Shi Q Y, Huo J J, Zheng Y R, et al. Influence of Mo and Ru additions on the creep behavior of $\mathrm{Ni}$-based single crystal superalloys at $1100{ }^{\circ} \mathrm{C}$. Materials Science and Engineering: $\mathrm{A}$, 2018, 725: 148-159.

[11] Zhu L, Li J S, Tang B, et al. Microstructure evolution and mechanical properties of diffusion bonding high $\mathrm{Nb}$ containing TiAl alloy to Ti ${ }_{2} \mathrm{AlNb}$ alloy. Vacuum, 2019, 164: 140-148.
[12] Wu Y W, Hu R, Yang J R. On the eutectoid decomposition of $\alpha \rightarrow \gamma+T_{1}$ in a Ru-containing TiAl alloy. Journal of Alloys and Compounds, 2019, 790: 42-47.

[13] Chen Q, Ma H G, Li X J, et al. Synergistic optimization of the thermoelectric properties of $\mathrm{Zn}_{0.98} \mathrm{Al}_{0.02} \mathrm{O}$ using high-pressure and high-temperature treatment. Journal of Alloys and Compounds, 2020, 844: 156124.

[14] Liu R X, Zheng J, Godlewski L, et al. Influence of pore characteristics and eutectic particles on the tensile properties of Al-Si-Mn-Mg high pressure die casting alloy. Materials Science and Engineering: A, 2020, 783: 139280.

[15] Jie J C, Zou C M, Wang H W, et al. Enhancement of mechanical properties of Al-Mg alloy with a high Mg content solidified under high pressures. Scripta Materialia, 2011, 64(6): 588-591.

[16] Liu X, Ma P, Jia Y D, et al. Solidification of Al-xCu alloy under high pressures. Journal of Materials Research and Technology, 2020, 9(3): 2983-2991.

[17] Wang H W, Zhu D D, Zou C M, et al. Evolution of the microstructure and nanohardness of Ti-48at.\%Al alloy solidified under high pressure. Materials and Design, 2012, 34: 488-493.

[18] Ma Y, Cuiuri D, Li H J, et al. The effect of postproduction heat treatment on $\mathrm{Y}$-TiAl alloys produced by the GTAWbased additive manufacturing process. Materials Science and Engineering: A, 2016, 657: 86-95.

[19] Zhang K R, Hu R, Li J G, et al. Grain refinement of 1at.\% Ta-containing cast TiAl-based alloy by cycli air-cooling heat treatment. Materials Letters, 2020, 274: 127940.

[20] Zhu D D, Wang H W, Zou C M, et al. High pressure solidification process and effect on nanohardness of Ti48at.\%Al alloy. International Journal of Cast Metals Research, 2012, 25(2): 126-128.

[21] Dey S R, Hazotte A, Bouzy E. Crystallography and phase transformation mechanisms in TiAl-based alloys - A synthesis. Intermetallics, 2009, 17(12): 1052-1064.

[22] Blackburn M J. The science technology and application of Ti. Oxford: Pergamon Press, 1970: 633-643.

[23] Ramanujan R V, Maziasz P J, Liu C T. The thermal stability of the microstructure of $y$-based titanium aluminides. Acta Materialia, 1996, 7(44): 2611-2642.

[24] Livingston J D, Cahn J W. Discontinuous coarsening of aligned eutectoids. Acta Metallurgica, 1974, 22(4): 495-503.

[25] Seung J Y, Soo W N. Investigation of $\alpha_{2} / Y$ phase transformation mechanism under the interaction of dislocation with lamellar interface in primary creep of lamellar TiAl alloys. Materials Science and Engineering: A, 2002, 329-331: 898-905.

[25] Göken M, Kempf M, Nix W D. Hardness and modulus of the lamellar microstructurein PST-TiAl studied by nanoindentations and AFM. Acta Materialia, 2001, 49(5): 903-911. 